\title{
Antiproliferative and pro-apoptotic activity of eugenol-related biphenyls on malignant melanoma cells
} Marina Pisano슬 Gabriella Pagnan ${ }^{2}$, Monica Loi ${ }^{1}$, Maria Elena Mura1, Maria Giovanna Tilocca ${ }^{1}$, Giuseppe Palmieri ${ }^{1}$, Davide Fabbri1, Maria Antonietta Dettori ${ }^{1}$, Giovanna Delogu ${ }^{1}$, Mirco Ponzoni ${ }^{\dagger 2}$ and Carla Rozzo*+1

\begin{abstract}
Address: ${ }^{1}$ Bio-molecular Chemistry Institute, National Research Council, Sassari, Italy and ${ }^{2}$ Differentiation Therapy Unit, Laboratory of Oncology, "G.Gaslini" Children's Hospital, Genova, Italy

Email: Marina Pisano - marina.pisano@icb.cnr.it; Gabriella Pagnan - gabriellapagnan@ospedale-gaslini.ge.it; Monica Loi - matlok@hotmail.it; Maria Elena Mura - mariaelena20@supereva.it; Maria Giovanna Tilocca - maria.giovanna.tilocca@icb.cnr.it;

Giuseppe Palmieri - palmierig@icb.cnr.it; Davide Fabbri - davide.fabbri@icb.cnr.it; Maria Antonietta Dettori - a.dettori@icb.cnr.it;

Giovanna Delogu - giovanna.delogu@icb.cnr.it; Mirco Ponzoni - mircoponzoni@ospedale-gaslini.ge.it; Carla Rozzo* - carla.rozzo@icb.cnr.it

* Corresponding author †Equal contributors
\end{abstract}

Published: 18 January 2007

Molecular Cancer 2007, 6:8 doi:10.1 186/1476-4598-6-8

This article is available from: http://www.molecular-cancer.com/content/6/1/8

(C) 2007 Pisano et al; licensee BioMed Central Ltd.

This is an Open Access article distributed under the terms of the Creative Commons Attribution License (http://creativecommons.org/licenses/by/2.0), which permits unrestricted use, distribution, and reproduction in any medium, provided the original work is properly cited.
Received: 22 November 2006

Accepted: 18 January 2007

\begin{abstract}
Background: Malignant melanoma is one of the most aggressive skin cancer and chemotherapeutic agents currently in use are still unsatisfactory. Prevention and early diagnosis are the only effective tools against this tumour whose incidence and mortality rates are highly increased during the last decades in fair skin populations. Therefore the search for novel therapeutic approaches is warranted. Aim of this work was to identify and test new compounds with antiproliferative and cytotoxic activity on melanoma cells. We tested eugenol together with six natural and synthetic eugenol-related compounds for their capability to inhibit cell growth on primary melanoma cell lines established from patients' tissue samples.
\end{abstract}

Results: Eugenol and isoeugenol monomers and their respective $\mathrm{O}$-methylated forms did not show to inhibit melanoma cells proliferation. Conversely, the dimeric forms (biphenyls) showed some antiproliferative activity which was mild for dehydrodieugenol, higher for its $0, O^{\prime}$-methylated form $\left(0, O^{\prime}\right.$-dimethyl-dehydrodieugenol), and markedly pronounced for the racemic mixture of the brominated biphenyl (6,6'-dibromo-dehydrodieugenol) (S7), being its enantiomeric form $(S)$ the most effective compared to the other compounds. Such activity resulted to be selective against tumour cells, without affecting cultured normal human skin fibroblasts. Dose and time dependence curves have been obtained for the enantiomeric form S7-(S). Then $I_{50}$ and minimal effective doses and times have been established for the melanoma cell lines tested. TUNEL and phosphatidylserine exposure assays demonstrated the occurrence of apoptotic events associated with the antiproliferative activity of S7-(S). Cytotoxic activity and apoptosis induced by treating melanoma cells with eugenol-related biphenyls was partially dependent by caspase activation.

Conclusion: Our findings demonstrate that the eugenol related biphenyl (S)-6,6'-dibromo-dehydrodieugenol elicits specific antiproliferative activity on neuroectodermal tumour cells partially triggering apoptosis and its activity should be further investigated on in vivo melanoma models in order to evaluate the real anticancer effectiveness on such tumour. 


\section{Background}

Malignant melanoma arises from the malignant transformation of epidermal melanocytes due to both environmental and genetic factors [1,2]. Melanoma is the most rapidly increasing malignancy in the white population [3] and, at the present, prevention and early detection represent the only effective approach to reduce its incidence. Little progress has been made in medical treatment of melanoma because of the absence of effective systemic therapies. Chemotherapy is not giving significant benefits and it is often associated to severe toxicity [4], while immunotherapy and vaccines are promising but still ineffective [5]. Patients with metastatic melanoma present a median survival of 4-10 months, depending on the involvement of the anatomic site (patients with disease confined to skin or lymph nodes have an overall survival longer than those with visceral involvement) [6].

It is therefore of primary interest to search for new therapeutic agents able to contrast this aggressive tumour. One of the developing strategies is to test some naturally occurring compounds whose chemopreventive properties in cancer therapy are already known [7].

Eugenol is a natural phenolic compound that is the main component of clove oil and it is present in reasonable amounts in several other spices like basil, cinnamon and bay leaves. It is used as antiseptic, analgesic and anti-bacterial agent in traditional medicine in Asia as well as in dentistry as main ingredient of cavity filling cement. Several biological activities of eugenol have been described in literature $[8,9]$ and it has been proved not to be carcinogenic neither mutagenic $[10,11]$. It possesses antiviral activity in vitro and in vivo against human herpesvirus [12]. Recently, eugenol was found to induce apoptosis in mast cells [13], melanoma cells [14] and HL-60 leukemia cells [15]. Moreover, it has been reported that dimers of eugenol related compounds have a better antioxidant activity than the original monomers [16-18] and that bis-eugenol shows stronger apoptotic activity than eugenol on leukemic cells [15]. Dimers of eugenol related compounds are hydroxylated biphenyls such as magnolol and honokiol, being the latters the main constituents of the stem bark of Magnolia officinalis, whose biological properties are well known in literature. Indeed, they both have antioxidant and antidepressant properties $[19,20]$ and recent reports have demonstrated that honokiol have antiangiogenic and antitumoural activity inducing apoptosis $[21,22]$.

On this basis, we screened a panel of eugenol related compounds in order to verify their possible ability to interfere with melanoma cells growth, as a first step toward the development of new therapeutic drug. We decided to compare eugenol and six related compounds differing for structure (monomeric or dimeric), chemical groups (hydroxylated, O-methylated and/or brominated) and specific conformational structure $[(S)$ or $(R)$ enantiomeric forms] for antitumour capability. We demonstrated that the byphenyl structure, the presence of bromine substitution and a specific stereo configuration of the molecule are important for the antiproliferative activity and induction of apoptotic cell death on melanoma cell lines.

\section{Results \\ Effect of eugenol derivatives (SI-S7) on the proliferation of melanoma cell lines}

Cell proliferation assays were performed to test the possible cytotoxicity of eugenol related compounds. As a first screening, nine melanoma cell lines (see Methods section for cell lines details) were grown up to 6 days in the presence of $100 \mu \mathrm{M}$ of each of the seven compounds S1 to S7, listed in Figure 1. None of the nine melanoma cell lines was inhibited by the treatment of $100 \mu \mathrm{M}$ eugenol (S1) or isoeugenol (S2) (Figure 2). As shown in Figure 2A, methyl-eugenol (S3) and methyl-isoeugenol (S4) treatments slightly inhibited melanoma cells growth (of about $20-40 \%)$. Dimeric forms were more effective. In particular, dehydrodieugenol (S5) decreased cell growth rate of about 40-60\%, O,O'-dimethyl-dehydrodieugenol (S6) caused a consistent growth inhibition of about $70-80 \%$, whereas the 6,6'-dibromo-dehydrodieugenol (S7) induced a quite complete growth inhibition (about $100 \%$ ) in all the nine melanoma cell lines (Figure 2A). Treatment with the latter compound showed an efficacy on cell proliferation better than the administration of 5 $\mu \mathrm{M}$ cisplatinum, a chemotherapeutic drug known as potent cytotoxic agent on cancer cell lines. On the basis of these results we decided to further investigate on the antiproliferative activity of compounds S3 to S7.

\section{Dose dependence of S3-S7}

Proliferation assays were then performed using three different concentrations of the eugenol-related compounds showing cytotoxic activity. Formerly, melanoma cell lines were treated with 100,10 , and $1 \mu \mathrm{M}$ of each S3-S7 and proliferation rates were evaluated after 6 days as described in the Materials and Methods section (Figure 2B). Cell growth inhibition at $100 \mu \mathrm{M}$ of these compounds somehow reproduced the data of Figure $2 \mathrm{~A}$. At lower concentration $(10 \mu \mathrm{M}) \mathrm{S} 3, \mathrm{~S} 4, \mathrm{~S} 5$, and S6 showed only partially specific inhibition of melanoma cell growth, while S7 confirmed its activity on all the tested cell lines (most of them presented a $80 \%$ or lower of growth rate, with few, more sensitive, cell lines, such as GR and 13443, whose growth rate was around the 50\%). None of the compounds tested at $1 \mu \mathrm{M}$ final concentration showed any significant activity. These results suggested that compounds S3-S6 have a much weaker anti-proliferative effect to be further tested in in vivo assays. Conversely, our interest has been focused on the potential biological activity of the S7 
<smiles>C=CCc1ccc(O)c(OCC)c1</smiles>

S1

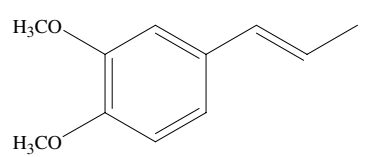

Metil-isoeugenol

S4

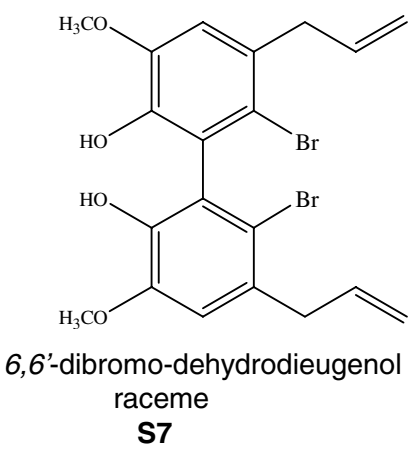

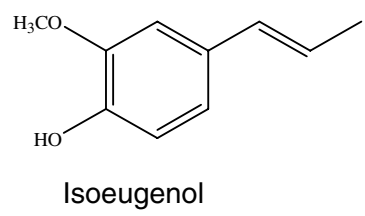

S2

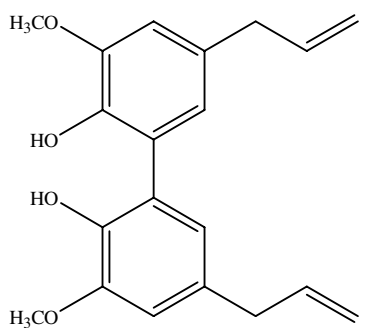

Dehydrodieugenol S5

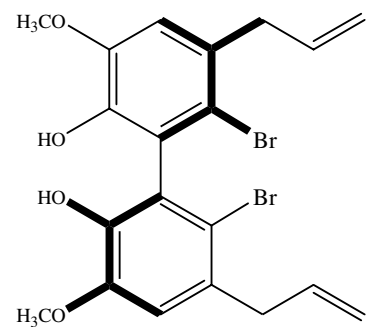

6,6'-dibromo-dehydrodieugenol enantiomer $(R)$

S7-( $R)$<smiles>C=CCc1ccc(OC)c(OC)c1</smiles>

Metil-eugenol

S3<smiles>C=CCc1cc(OC)c(OC)c(-c2cc(CC=C)cc(OC)c2OC)c1</smiles>

O,O'-dimethyl-dehydrodieugenol s6

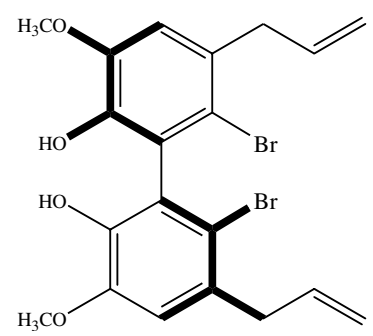

6,6'-dibromo-dehydrodieugenol enantiomer $(S)$ S7-(S)

Figure I

Chemical structures of eugenol and related compounds.

dimer. The S7 compound is a chiral molecule (Figure 1) therefore two atropo-enantiomers are evidenced at room temperature. Often, the two stereoisomers can show different biological activity, for this reason we decided to test the activity of both the enantiomers S7- $(S)$ and S7- $(R)$ on tumour cells.

\section{Enantiopure form S7-(S) is more active than both S7-(R) and their} racemic mixture

The dose-dependent effects on three melanoma cell lines (WM, GR, PNP) and on normal fibroblasts short term culture (as control) were tested using S7 racemic mixture, S7$(R)$ and S7- $(S)$. Graphics reported in Figure 3 show that the S7- $(S)$ enantiomeric form was more active on inhibiting melanoma cell proliferation than the two other forms and that normal fibroblasts were not affected by these treatments up to the concentration of $60 \mu \mathrm{M}$. $\mathrm{IC}_{50}$ values for each form of S7 on the melanoma cell lines tested are reported in Table 1.
To validate the efficacy of S7-(S) as novel putative anticancer agent for neuroectoderma-derived tumours, we tested its anti-proliferative activity also on neuroblastoma (NB) cells, the pediatric solid tumour sharing with melanoma the origin from neural crest cells. As reported in Table 1, S7-(S) was slightly more efficient on NB cells showing $\mathrm{IC}_{50}$ values less than $20 \mu \mathrm{M}$ after 5 days of treatments.

\section{Time dependence and anticancer specificity of S7-(S)}

Time-course experiments using $50 \mu \mathrm{M}$ S7-(S) up to 5 days showed that its anti-proliferative activity was already evident after 24 hours of treatment (30-60\% of growth inhibition), reaching $90-100 \%$ of growth inhibition after 3 treatments in the $5^{\text {th }}$ day (Figure $4 \mathrm{~A}$ ).

To simulate the activity of S7-(S) in vivo, we tested the response of melanoma cells to the drug after very short exposures. Indeed, wash-out experiments using $50 \mu \mathrm{M} \mathrm{S7-}$ $(S)$ up to 48 hours better defined the action time window 




\section{B}


$$
\begin{aligned}
& \square \text { LCP } \\
& \square \text { LCM } \\
& \square \text { PNP } \\
& \square \text { GR } \\
& \square \text { WM } \\
& \square 13443 \\
& \square \text { SK } \\
& \square \text { CN }
\end{aligned}
$$

Figure 2

Effect of eugenol derivatives on the growth of human melanoma cell lines. Nine melanoma cell lines were cultured (A) in presence of $100 \mu \mathrm{M}$ or (B) with various concentrations of each compound (SI-S7), for 6 days and cell proliferation was estimated as described in Material and Methods. Results are expressed as percent of cell growth and represent the average $( \pm$ standard deviation) of triplicate cultures performed twice. $5 \mu \mathrm{M}$ Cisplatinum was used as cytotoxic agent positive control. 

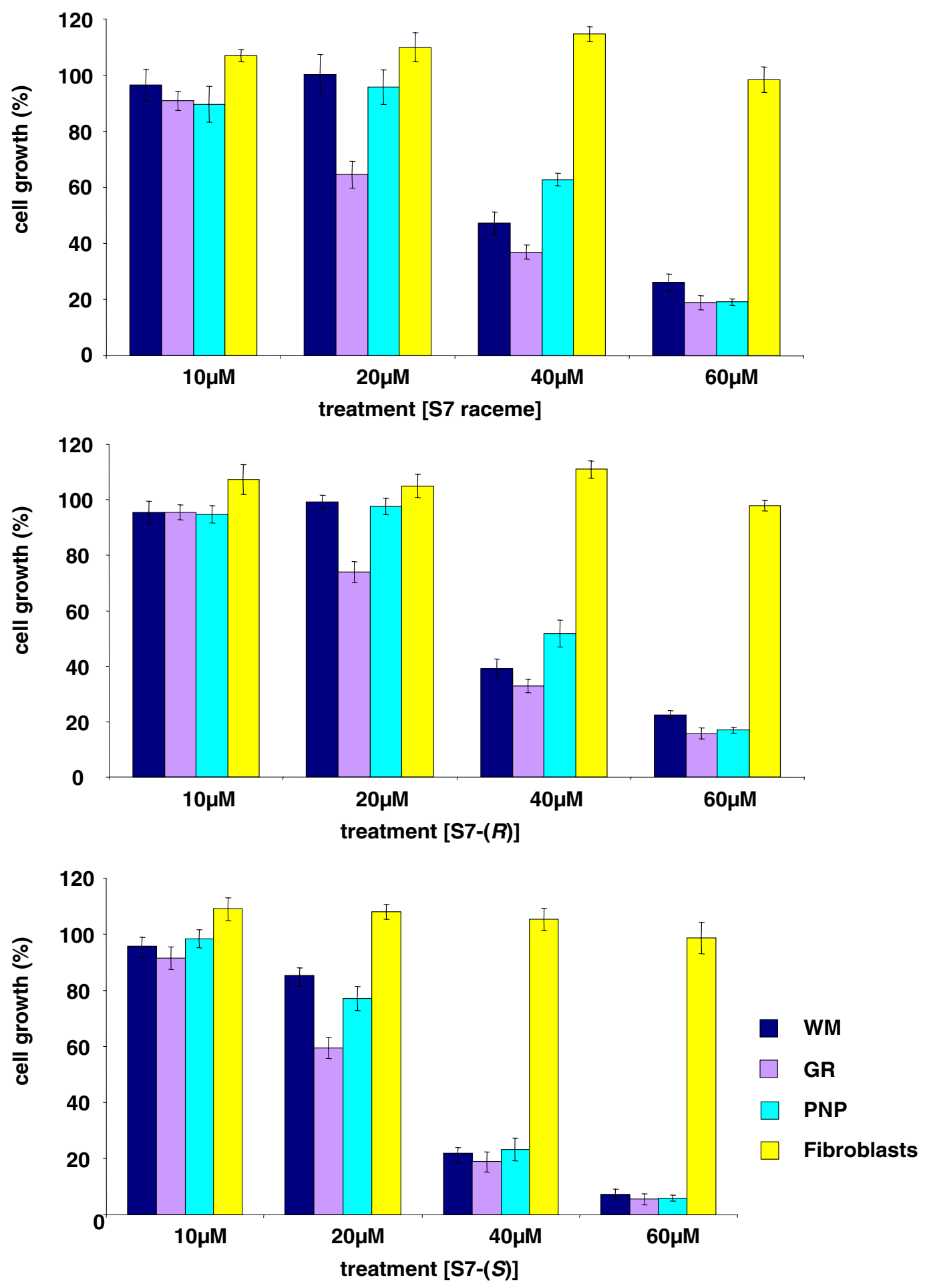

Figure 3

Dose-dependent $\mathbf{S 7}$ antiproliferative activity: comparison of raceme mixture with the enantiopure forms S7$(R)$ and S7-(S). Three melanoma cell lines and one short term culture of human fibroblasts were treated with various concentrations of S7, S7-(R) and S7-(S) for 3 days. Cell proliferation was estimated as described in Material and Methods. Results are expressed as percentage of cell growth and represent the average ( \pm standard deviation) of triplicate cultures performed twice. 


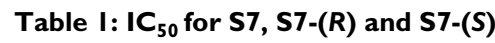

\begin{tabular}{cccc}
\hline \multicolumn{1}{c}{ IC $_{\mathbf{5 0}}[\mu \mathrm{M}]$} & & S7-(S) \\
\hline Cell lines & S7 raceme & S7-(R) & 27 \\
WM (MM) & 38,5 & 36 & 23 \\
GR (MM) & 30,0 & 31,5 & 29 \\
PNP (MM) & 46,0 & 41 & 19 \\
GILIN (NB) & n.d. & n.d. & 16 \\
LAN-5 (NB) & n.d. & n.d. & \\
\hline
\end{tabular}

Legend: MM (Malignant Melanoma)

NB (Neuroblastoma)

n.d. (not done)

of such compound establishing that a single administration of S7-(S) is sufficient to inhibit melanoma cell growth up to $80 \%$ for 48 hours with no effect on cell growth of normal fibroblasts (Figure 4B).

We then examined the effect of S7-(S) on the viability of cultured melanoma cells by trypan blue staining. Melanoma cells and fibroblasts were incubated with 50 $\mu \mathrm{M}$ S7-(S) for 24 hours and their viability was assessed. The results showed a statistically significant cytotoxic activity of S7-(S) on melanoma cells without affecting non-transformed cells (Figure 5A). Similar results were obtained with the other melanoma and NB cell lines (data not shown).

\section{Effects of S7-(S) on apoptosis in melanoma cell lines}

To determine whether the observed S7-(S)-induced reduction in viability of melanoma cells occurred via induction of apoptosis, we used TUNEL staining to measure DNA fragmentation and phosphatidylserine exposure as an early hallmark of apoptotic cell death in treated cells. As evidenced in Panels $d$ and $e$ of Figure 5C, a small, but consistent proportion of TUNEL-positive melanoma cells (15-20\% apoptotic fraction) was detected after 24 hours of treatment with $50 \mu \mathrm{M} \mathrm{S7}-(S)$, while no evidences of apoptosis were observed in human fibroblasts (Fig. 5C, panel $f$ ). Moreover, the same treatment of melanoma cells with S7- $(S)$ induced a significant increase in the number of cells expressing phosphatidylserine on cell surface (Figure 5B).

Besides nuclear condensation and appearance of oligonucleosomal DNA, induction of apoptosis may involve activation of aspartate specific cysteine proteases or caspases [23]. Melanoma cells were treated for 24 hours with 50 $\mu \mathrm{M} \mathrm{S7-}(S)$ in the presence or absence of pan-caspase inhibitor (z-VAD-fmk, $100 \mu \mathrm{M})$. Pan-caspase inhibitor significantly reduced the number of trypan blue-positive cells (Figure 5A) and significantly blocked S7-(S)-triggered apoptosis (Figure 5B).

\section{Discussion}

To verify the possible anti-proliferative effect of some eugenol derivatives as a first step toward the development of novel putative anticancer agents, we tested eugenol and isoeugenol as well as five eugenol-related compounds for their capability to inhibit cell growth and viability on a panel of melanoma cell lines.

Previous report showed that eugenol, but not its isomer isoeugenol, inhibit melanoma cell proliferation by arresting cells in the $S$ phase of cell cycle and inducing apoptosis [14]. Moreover, eugenol and creosol dimers are widely reported as cytotoxic and antioxidant agents inducing apoptosis on HL-60 leukemia cells $[15,17]$, with much stronger effects than their original monomers. We have previously described the synthesis and purification of the two enantiopure forms of 6,6'-dibromo-dehydrodieugenol and its antinociceptic activity $[24,25]$. In the present study, we demonstrate that this compound, a brominated dimer of eugenol, is the most potent eugenol-derivative able to show antiproliferative action on melanoma cells, partially triggering apoptosis, and it could be considered a potential candidate to be tested in in vivo models as anticancer agent. Moreover, we show that the enantiopure form (aS) of such compound is much more active, as antiproliferative agent, than both the racemic mixture and the enantiopure $(R)$ form. This is a frequent property of chiral compounds whose biological activity is often related to a defined absolute configuration. Stereo-isomeric forms of same compound may show very different properties and bio-activity, like different degree of absorption and clearance, different metabolic pathways and toxicological characteristics [26]. To date, brominated biphenyls have been described to have a role in antimicrobial and antiviral therapies $[27,28]$. Our findings point out the anti-proliferative properties of eugenol related compounds, whose dimeric forms, conversely from the eugenol monomeric form (which did not show any activity on inhibiting melanoma cell growth), are able to block tumour cell growth. Indeed, none of the nine melanoma cell lines 

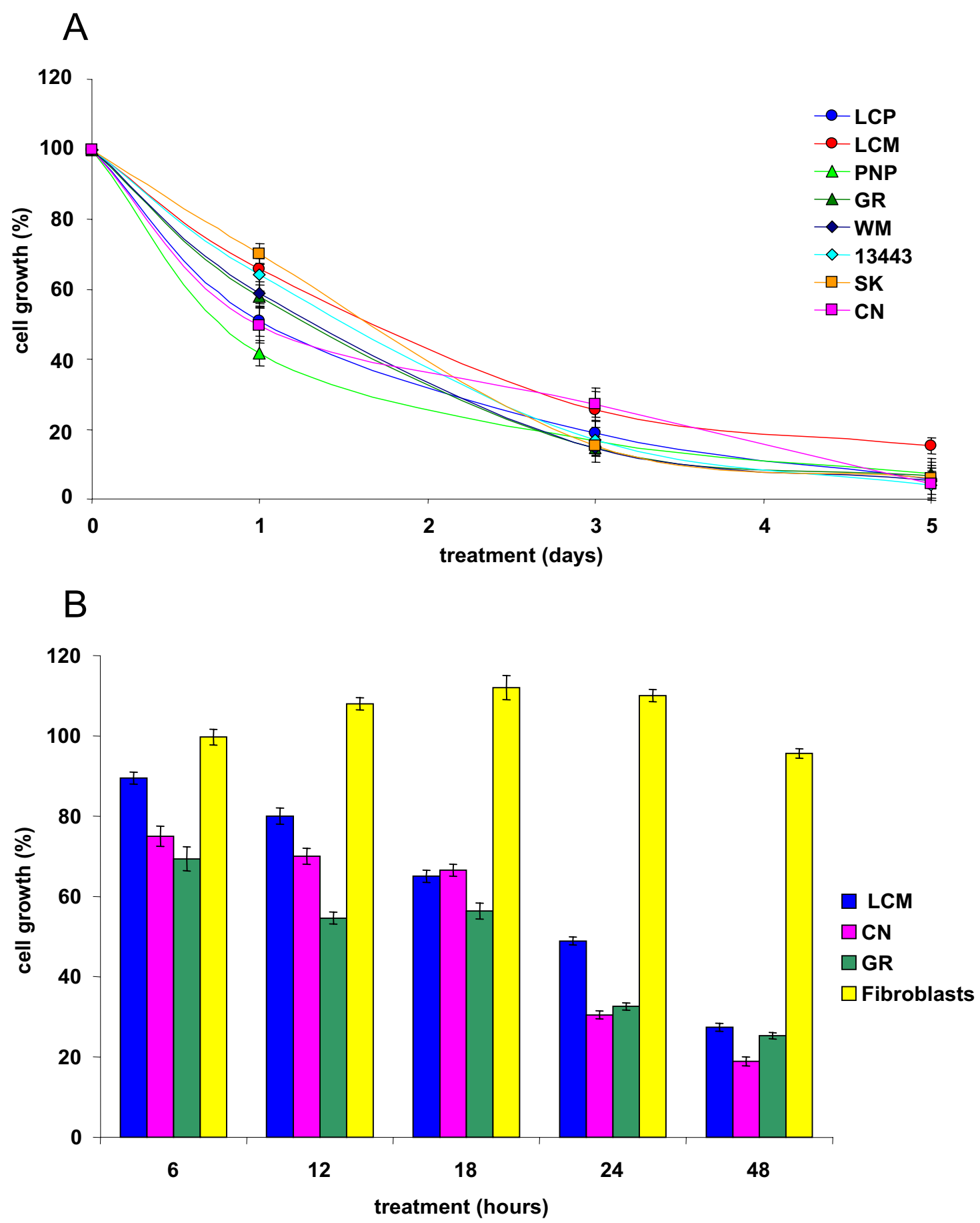

\section{Figure 4}

Time-dependent antiproliferative effect of S7-(S) on melanoma cells. (A) Eight melanoma cell lines were treated with $50 \mu \mathrm{MS7}-(\mathrm{S})$ and cell proliferation was estimated at the different points, as described in Material and Methods. Results are expressed as percentage of cell growth and represent the average ( \pm standard deviation) of triplicate cultures performed twice. (B) S7-(S) wash-out assay. Three melanoma cell lines and one short term culture of human fibroblasts were treated with 50 MM S7-(S) for various times (6-12-18-24-48 hours), then washed and incubated with S7-(S) free medium. Cell proliferation was estimated 48 hours after initiation of treatment, as described in Material and Methods. Results are expressed as percentage of cell growth and represent the average ( \pm standard deviation) of triplicate cultures performed twice. 
A

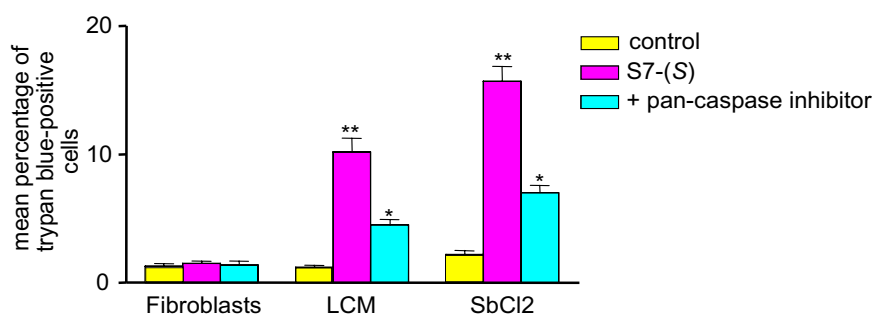

B


\section{Figure 5}

Effect of S7-(S) on cell viability and apoptosis in melanoma cells. (A) Melanoma cells and normal fibroblasts were incubated with $50 \mu \mathrm{M}$ S7-(S) or solvent (control) for 24 hours, and cell death was determined by trypan blue staining. Results are expressed as mean number of trypan blue-positive cells in triplicate cultures from two independent experiments. Cells were also pre-treated for I hour with the pan-caspase inhibitor before S7-(S) treatment. $P$ values for S7-(S) versus control and for inhibitor versus S7-(S) were calculated by Student's t-test with Welch correction: *, $P<.05$; **, $P<.01$. (B) Effect of S7-(S) on phosphatidylserine exposure on melanoma cells. Human fibroblasts and melanoma cell lines were incubated in the presence or absence of $50 \mu \mathrm{M}$ S7-(S) for 24 hours. Cells were also pre-treated for I hour with the pan-caspase inhibitor before S7-(S) treatment. Cells were double stained with annexin V-FITC to detect phosphatidylserine exposure and propidium iodide to detect DNA and analysed by flow cytometry. Results are expressed as mean percentage of apoptotic cells from three independent experiments. $P$ values for S7-(S) versus control and for inhibitor versus S7-(S) were calculated by Student's t-test with Welch correction: *, $P<.05$; **, $P<.01$; ***, $P<.00 \mathrm{I}$. (C) Effect of S7-(S) on DNA fragmentation in melanoma cells. GR-mel (a, d), Sbcl2 (b, e) melanoma cell lines and human fibroblasts (c, f) were treated with $50 \mu \mathrm{M}$ (d, e, f) S7-(S) or grown in S7-(S) free medium (control a, b, c) for 24 hours and apoptotic cells (red) were stained by the TUNEL assay. Cell nuclei (blue) were stained with DAPI. 
(including Sbcl2 cell line used by Ghosh and collaborators [14]) was inhibited by treatment with $100 \mu \mathrm{M}$ eugenol (S1) and isoeugenol (S2) (see Figure 2). This contrasting data could be due to the different culture conditions used in the laboratories. In our experiments, the anti-tumour capability notably increased in the methylated and brominated dimeric forms of eugenol, which indeed show better cytotoxic activity than the monomeric forms. The importance of the dimeric structure is also shown by other compounds of natural origin, such as the hydroxylated biphenyls magnolol and honokiol, whose biological properties are well known in literature (honokiol has been proven to be a potent anti-angiogenic and anti-tumoural compound inducing apoptosis $[21,22])$.

Moreover, the S7-(S) compound seems to have a quite specific activity on tumour cells, since it is not toxic to normal human diploid fibroblasts when used at the same conditions that completely arrest melanoma cells growth and induced cell death. Wash-out experiments were performed to reproduce in vivo like conditions, treating cells with a single dose of the compound to be tested, and washing it out after increasing time intervals, in order to mimic drug processing and clearance occurring in tumour tissue [29]. Such experiments demonstrated that a single dose of $50 \mu \mathrm{M} \mathrm{S7-(S)}$ drastically inhibits melanoma cell growth up to $80 \%$ after 48 hours of treatment without affecting cell growth in normal cells (see Figure 4B).

We finally addressed the question whether inhibition of cell proliferation and induction of cell death in melanoma cells by S7- $(S)$ is mediated by apoptosis. Although, our findings strongly suggest a pivotal role of caspases in S7-(S)-triggered apoptosis, further studies will better clarify the role of upstream signals - between drug exposure and caspase activation - or the involvement of cell death mechanisms other than apoptosis, such as autophagy and mitotic catastrophe [30,31].

\section{Conclusion}

In conclusion this work demonstrates that the biphenyl eugenol-derivative enantiomer (S)-6,6'-dibromo-dehydrodieugenol, is an effective cytotoxic agent for melanoma and neuroblastoma cells and it is endowed with apoptotic inducing capability. Moreover its action is selective on tumour cells not interfering with normal cells growth. Our data support the effectiveness of biphenyl as dimeric structures with specific substitute and stereo configuration in inhibiting the malignant proliferation of neuroectodermal tumour cells in vitro. Further investigation of S7- $(S)$ in mouse cancer models will contribute to better understand its in vivo activity against malignant cells and its real toxicity in normal tissues. Assessment of the molecular mechanism underlying the activity of this compound as well as biological test of similar substances to be active at lower concentration will represent the aims of future research efforts.

\section{Methods \\ Cell lines}

Malignant melanoma cell lines WM266-4 (WM), SK-Mel28 (SK), LCP-Mel (LCP), LCM-Mel (LCM), PNP-Mel (PNP), CN-MelA (CN), 13443, GR-Mel (GR) were kindly provided by Drs. D. Castiglia and S. D'Atri at the Institute "Dermopatico dell'Immacolata" in Rome. They were established as primary short term cell cultures starting from tumour samples of donors patients with documented diagnosis of malignant melanoma after obtaining their informed consent, as previously described [32]. $\mathrm{SbCl} 2$ melanoma cell line [33] and the human Neuroblastoma (NB) cell lines, GI-LI-N [34] and LAN-5 [35], were used between passages 50 and 75 .

Short term cultures of normal human fibroblasts from healthy donors were established at National Cancer Institute in Naples and at Gaslini Children's hospital and used as controls.

Cells were cultured to confluence in tissue culture flasks using either Dulbecco's minimal essential medium (DMEM) or RPMI medium (Invitrogen, Carlsbad, CA) supplemented with $10 \%$ FBS and penicillin/streptomycin [100 IU $(50 \mu \mathrm{g}) / \mathrm{ml}]$ in a humidified $5 \% \mathrm{CO}_{2}$ atmosphere at $37^{\circ} \mathrm{C}$, as previously described $[36,37,33]$.

\section{Eugenol and derivatives}

Eugenol (S1) and isoeugenol (S2) were purchased from Sigma-Aldrich (St. Louis, MO), purity 99\% and 98\% respectively. Isoeugenol was a 90:10 mixture of trans:cis isomeric forms. Eugenol and isoeugenol derivatives S3S7 (Fig. 1) were synthesized at the C.N.R., Bio-molecular Chemistry Institute in Sassari, as previously described [24]. S1-S4 were solved in ethanol 99\% while S5-S7 in DMSO, all at a stock dilution of $100 \mathrm{mM}$, and then used for cells treatments at concentration between $100 \mu \mathrm{M}$ and $1 \mathrm{nM}$ in complete medium. Chemical structures and nomenclature of the compounds used are reported in Figure 1.

The chemotherapeutic agents Cisplatinum and Etoposide (Teva Pharma B.V., Holland) were used as cytotoxic positive controls at concentration of $5 \mu \mathrm{M}$ and $25 \mu \mathrm{M}$, respectively, in complete medium.

\section{Cell proliferation assay}

Cells were plated $\left(3 \times 10^{3} /\right.$ well $)$ in 96-well plates in their complete medium. After 24 hours, medium was removed and replaced on days 1, 3 and 5 in quadruplicate by the same medium (control) or supplemented with various 
S1-S7 doses as described in legend of figures. Cells were observed with inverted microscope every 24 hours to check on morphological changes, suffering or cell death. The percentage of cell proliferation was estimated on day 6 by the colorimetric assay of Kueng et al. [38] modified as follows: cells were fixed for $20 \mathrm{~min}$ at room temperature with $4 \%$ paraformaldehyde (PFA), stained with $0.1 \%$ crystal violet in $20 \%$ methanol for 20 min, washed with PBS, solubilized with $10 \%$ acetic acid and read at $595 \mathrm{~nm}$ in a microplate reader (SpectraFluor Plus, Tecan, Austria).

To assess the impact of drug exposure time on cell proliferation, washout experiments were also performed according to the method shown by Keshelava et al. [39]. Briefly, S7-(S) containing medium was removed from the cultures after 6-12-18-24 hours by two PBS washings. Cells were subsequently covered with fresh drug-free medium and incubated until 48 hours and cell proliferation rate was evaluated by the same colorimetric assay.

\section{Cell viability assay}

Following the indicated treatments (see legend of Figure $5)$, cells were incubated with trypan blue, for one minute at $37^{\circ} \mathrm{C}$. Trypan blue-positive and total cells were counted per microscope field, for a total of four fields for each combination. The proportion of dead cells was calculated by dividing the number of dead cells by that of total cells/ field. Alternatively, viable cell number was counted. In some experiments, cells were cultured for 1 hour with 100 $\mu \mathrm{M}$ Z-VAD-FMK (pan-caspases inhibitor, Sigma Aldrich, St. Louis, MO) before S7- $(S)$ treatments, and then viability was evaluated.

\section{Apoptosis assays \\ TUNEL assay}

Melanoma cells $\left(5 \times 10^{4} /\right.$ well $)$ were plated in 8 wellchamber slides and, after 24 hours of culture, were treated with S7-(S) $(50 \mu \mathrm{M}$ and $100 \mu \mathrm{M})$ or $25 \mu \mathrm{M}$ Etoposide. After a further 24 hours, DNA cleavage was assessed by enzymatic end-labeling of DNA strand breaks using a commercial kit (In Situ Cell Death Detection Kit, Roche, Penzberg, Germany), according to the manufacturer's instructions. Briefly, slides with adherent cells were airdried and fixed in 4\% PFA for 1 hour at room temperature, washed in PBS and permeabilized with $0.1 \%$ Triton X-100 and $0.1 \%$ sodium citrate for 2 minutes at $4{ }^{\circ} \mathrm{C}$; after rinsing, slides were incubated with $50 \mu$ of TUNEL reaction mixture, containing terminal deoxynucleotidyl transferase (TdT) and TMR red-labeled dUTP, in a humidified atmosphere for 1 hour at $37^{\circ} \mathrm{C}$ in the dark. Rinsed slides

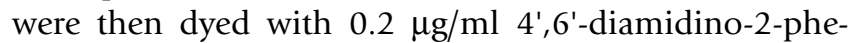
nylindole (DAPI) (Vector Laboratories, Burlingame, CA) in PBS, for nuclear counterstaining, and then washed again with PBS. Finally slides were coverslipped with Mowiol 4-88 mounting medium (Calbiochem, San
Diego, CA). Cells were analyzed under a Olimpus BX 50 fluorescent microscope with appropriate DAPI and TMR red filter sets. The images were acquired with a high-sensitivity monochrome charge-coupled device (CCD) camera.

\section{Phosphatidylserine detection}

Phosphatidylserine (PS) exposure was assessed with a human Annexin V- fluorescein isothiocyanate (FITC) Kit (Bender MedSystems, Vienna, Austria). Briefly, cultured and S7- $(S)$ treated primary melanoma cells were collected, washed and incubated for 10 minutes with $5 \mu \mathrm{l}$ Annexin V-FITC, washed once with PBS, resuspended in $190 \mu \mathrm{l}$ prediluted binding buffer containing $10 \mu \mathrm{l}$ of a $20 \mu \mathrm{g} / \mathrm{ml}$ propidium iodidide (PI) I stock solution and examined by two colour flow cytometry using a FACScan (Beckton Dickinson, Franklin Lakes, NJ). FITC and PI fluorescence intensities were recorded through a 520-530 (FL1-H) and 575 (FL2-H) nm filters, respectively. At least 10,000 events were collected in each dot plot and analyzed using Cell Quest software (Beckton Dickinson, Franklin Lakes, NJ). Cells that did not stain for either Annexin V-FITC or PI were viable and did not undergo measurable apoptosis; those that stained for Annexin FITC, but not for PI, were in the early stages of apoptosis; cells that stained positive for both Annexin V-FITC and PI were either in the late stages of apoptosis or necrotic, as previously described [40].

\section{Statistical methods}

Results are expressed as mean \pm standard deviation. All in vitro data are from at least three independent experiments. The statistical significance of differential findings between experimental groups and controls was determined by Student's t-test with Welch correction. These findings were considered significant if two-tailed $P$ values were $<0.05$.

\section{Competing interests}

The author(s) declare that they have no competing interests.

\section{Authors' contributions}

$M$ Pisano carried out cell cultures, cell proliferation assays, TUNEL assays and drafted the manuscript. G Pagnan carried out cell viability assays and phospatidylserine detection. ML, MEM and MGT participated to cell cultures and cell proliferation assays. G Palmieri contributed to the final drafting and critical revision of the manuscript. DF, MAD and GD performed the chemical synthesis of eugenol-and isoeugenol-derivatives and the resolution of S7. $M$ Ponzoni performed statistical analysis and together with CR conceived of the study, participated in its design and coordination and carried out the final drafting of the manuscript. 


\section{Acknowledgements}

We thank Drs. Daniele Castiglia and Stefania D'Atri, from the Institute "Dermopatico dell'Immacolata" in Rome, and Dr. Paola Giuliano, from the National Cancer Institute in Naples, for providing melanoma cell lines and short term fibroblast cell cultures, respectively.

Work supported by Fondazione Italiana per la lotta al Neuroblastoma, Associazione Italiana per la Ricerca sul Cancro (AIRC), and Ministry of Health.

G. Pagnan is a recipient of a "Fondazione Italiana per la Lotta al Neuroblastoma" fellowship.

\section{References}

I. Bataille V: Genetic epidemiology of melanoma. Eur J Cancer 2003, 39: $134 \mid-1347$

2. Chin $\mathrm{L}$ : The genetics of malignant melanoma: lessons from mouse and man. Nat Rev Cancer 2003, 3(8):559-570.

3. Armstrong $B K$, Kricker $A$ : The epidemiology of $U V$ induced skin cancer. JPhotochem Photobiol B 200I, 63:8-18.

4. Margolin KA: Biochemotherapy for melanoma: rational therapeutics in the search for weapons of melanoma destruction. Cancer 2004, 101:435-438.

5. Sondak VK, Sabel MS, Mule JJ: Allogeneic and autologous melanoma vaccines: where have we been and where are we going? Clin Cancer Res 2006, I 2:2337s-234 Is.

6. Balch CM, Soong SJ, Gershenwald JE, Thompson JF, Reintgen DS, Cascinelli N, Urist M, McMasters KM, Ross MI, Kirkwood JM, Atkins MB, Thompson JA, Coit DG, Byrd D, Desmond R, Zhang Y, Liu PY, Lyman GH, Morabito A: Prognostic factors analysis of 17,600 melanoma patients: validation of the American Joint Committee on Cancer melanoma staging system. J Clin Oncol 200I, 19:3622-3634.

7. Dorai T, Aggarwal BB: Role of chemopreventive agents in cancer therapy. Cancer Letters 2004, 2 15:129-140.

8. Rasheed A, Laekeman G, Totte J, Vietinch AJ, Herman AG: Eugenol and prostaglandin biosynthesis. New Engl] Med I 984, 3 I 0:50-5I.

9. Burt S: Essential oils: their antibacterial properties and potential applications in foods-a review. Int J Food Microbiol 2004, 94:223-253.

10. Miller JA, Swanson AB, Miller EC: The metabolic activation of safrole and related naturally occurring alkenylbenzenes in relation to carcinogenesis by the compound. In Naturally occurring carcinogens-mutagens and modulators of carcinogenesis Edited by: Miller EC, Miller JA, Hirono I, Sugimura T, Takayama S. Tokyo: Japan Sci. Soc. Press/Baltimore: Univ. Park Press; 1979: III-I 25.

II. Stich HF, Stich W, Lam PP: Potentiation of genotoxicity by concurrent application of compounds found in betel quid: arecoline, eugenol, quercetin, chlorogenic acid and Mn2+. Mutat Res 1981, 90:355-363.

12. Benencia $F$, Courreges MC: In vitro and in vivo activity of eugenol on human herpesvirus. Phytother Res 2000, I 4:495-500.

13. Park BS, Song YS, Yee SB, Lee BG, Seo SY, Park YC, Kim JM, Kim HM, Yoo YH: Phospho-ser I5-p53 translocates into mitochondria and interacts with $\mathrm{Bcl}-2$ and $\mathrm{Bcl}-\mathrm{xL}$ in eugenol-induced apoptosis. Apoptosis 2005, 10:193-200.

14. Ghosh R, Nadiminty L, Fitzpatrick JE, Alworth WL, Slaga TJ, Kumar AP: Eugenol causes melanoma growth suppression through inhibition of E2FI transcriptional activity. J Biol Chem 2005, 280:58|2-58|9.

15. Okada N, Hirata A, Murakami Y, Shoji M, Sakagami H, Fujisawa S: Induction of cytotoxicity and apoptosis and inhibition of cyclooxigenase-2 gene expression by eugenol-related compounds. Anticancer Res 2005, 25:3263-3270.

16. Ogata M, Hoshi M, Urano S, Endo T: Antioxidant activity of eugenol and related monomeric and dimeric compounds. Chem Pharm Bull 2000, 48: 1467-1469.

17. Fujisawa S, Atsumi T, Kadoma $\mathrm{Y}$, Sakagami H: Antioxidant and prooxidant action of eugenol-related compounds and their cytotoxicity. Toxicology 2002, 177:39-54.

18. Saito M, Sakagami H, Fujisawa S: Cytotoxicity and apoptosis induction by butylated hydroxyanisole (BHA) and butylated hydroxytoluene (BHT). Anticancer Res 2003, 23:4693-4701.
19. Lo YC, Teng CM, Chen CF, Chen CC, Hong CY: Magnolol and honokiol isolated from Magnolia officinalis protect rat heart mitochondria against lipid peroxidation. Biochem Pharmacol 1994, 47:549-553.

20. Nakazawa T, Yasuda T, Ohsawa K: Metabolites of orally administered Magnolia officinalis exstract in rats and man and its antidepressant-like effects in mice. J Pharm Pharmacol 2003, 55:I583-I59I.

21. Bai $X$, Cerimele F, Ushio-Fukai M, Waqas M, Campbell PM, Govindarajan B, Der CJ, Battle T, Frank DA, Ye K, Murad E, Dubiel W, Soff G, Arbiser JL: Honokiol, a small molecular weight natural product, inhibits angiogenesis in vitro and tumour growth in vivo. J Biol Chem 2003, 278:3550I-35507.

22. Battle TE, Arbiser J, Frank DA: The natural product honokiol induces caspase-dependent apoptosis in B-cell chronic lymphocytic leukemia (B-CLL) cells. Blood 2005, 106:690-697.

23. Thornberry NA: Caspases: key mediators of apoptosis. Chem Biol 1998, 5:R97-103.

24. Delogu G, Fabbri D, Dettori MA, Forni A, Casalone G: Enantiopure 2,2'-dihydroxy-3.3'-dimethoxy-5,5'-diallyl-6,6'-dibromo-I,I'biphenyl: a conformationally stable C2-dimer of a eugenol derivative. Tetrahedron: Asymmetry 2004, I 5:275-282.

25. Peana AT, Chessa G, Carta G, Delogu G, Fabbri D: Eugenol, biseugenol and synthesized related-dimer compounds produce antinociception in the acetic acid-induced-writhing responses. Curr Topics Phytochem 2004, 6: |37-143.

26. Lednicer D: Strategies for organic drug synthesis and design New York, NY: John Wiley and Sons, Inc; 1998.

27. Fujihashi $T$, Hara $H$, Sakata $T$, Mori $K$, Higuchi $H$, Tanaka A, Kaji H, Kaji A: Anti-human immunodeficiency virus (HIV) activities of halogenated gomisin J derivatives, new nonnucleoside inhibitors of HIV type I reverse transcriptase. Antimicrob Agents Chemother 1995, 39:2000-2007.

28. Chen DF, Zhang S, Xie L, Xie JX, Chen K, Kashiwada Y, Zhou BN Wang P, Cosentino LM, Lee KH: Anti AIDS agents - XXVI. Structure-activity correlations of gomisin-G-related antiHIV lignans from Kadsura interior and of related synthetic analogues. Bioorg Med Chem 1997, 5:1715-1723.

29. Brignole C, Marimpietri D, Pastorino F, Nico B, Di Paolo D, Cioni M, Piccardi F, Cilli M, Pezzolo A, Corrias MV, Pistoia V, Ribatti D, Pagnan G, Ponzoni M: Effect of Bortezomib on Human Neuroblastoma Cell Growth, Apoptosis, and Angiogenesis. J Natl Cancer Inst 2006, 98: II42-II57.

30. Brown JM, Attardi LD: The role of apoptosis in cancer development and treatment response. Nat Rev Cancer 2005, 5:23I-237.

31. Kroemer G, Martin SJ: Caspase-independent cell death. Nat Med 2005, I I:725-730.

32. Abdel-Malek ZA, Swope VB, Nordlund JJ, Medrano EE: Proliferation and propagation of human melanocytes in vitro are affected by donor age and anatomical site. Pigment Cell Res 1994, 7:116-122.

33. Montaldo PG, Pagnan G, Pastorino F, Chiesa V, Raffaghello L, Kirchmeier M, Allen TM, Ponzoni M: N-(4-hydroxyphenyl) retinamide is cytotoxic to melanoma cells in vitro through induction of programmed cell death. Int J Cancer 1999, 81:262-267.

34. Cornaglia-Ferraris P, Sansone R, Mariottini GL, Longo L, Tonini GP. Evidence of loss of N-myc amplification during the establishment of a human neuroblastoma cell line. Int J Cancer 1990, 45:578-579.

35. Seeger RC, Rayner SA, Banerjee A, Chung H, Laug WE, Neustein HB, Benedict WF: Morphology, growth, chromosomal pattern and fibrinolytic activity of two new human neuroblastoma cell lines. Cancer Res 1977, 37:1364-137I.

36. Ponzoni M, Bocca P, Chiesa V, Decensi A, Pistoia V, Raffaghello L, Rozzo C, Montaldo PG: Differential effects of N-(4-hydroxyphenyl)retinamide and retinoic acid on neuroblastoma cells: apoptosis versus differentiation. Cancer Res 1995, 55:853-86I.

37. Pagnan G, Montaldo PG, Pastorino F, Raffaghello L, Kirchmeier M, Allen TM, Ponzoni M: GD2-mediated melanoma cell targeting and cytotoxicity of liposome-entrapped fenretinide. Int J Cancer 1999, $81: 268-274$

38. Kueng W, Silber E, Eppenberger U: Quantification of Cells Cultured on 96-Well Plates. Anal Biochem 1989, 182:16-19.

39. Keshelava N, Tsao-Wei D, Reynolds CP: Pyrazoloacridine is active in multidrugresistant neuroblastoma cell lines with nonfunctional p53. Clin Cancer Res 2003, 9:3492-3502. 
40. Marimpietri D, Nico B, Vacca A, Mangieri D, Catarsi P, Ponzoni M: Synergistic inhibition of human neuroblastoma-related angiogenesis by vinblastine and rapamycin. Oncogene 2005, 24:6785-6795.

Publish with Bio Med Central and every scientist can read your work free of charge

"BioMed Central will be the most significant development for disseminating the results of biomedical research in our lifetime. " Sir Paul Nurse, Cancer Research UK

Your research papers will be:

- available free of charge to the entire biomedical community

- peer reviewed and published immediately upon acceptance

- cited in PubMed and archived on PubMed Central

- yours - you keep the copyright

Submit your manuscript here:

http://www.biomedcentral.com/info/publishing_adv.asp
BioMedcentral 